\title{
Design of an Electrochemical Micromachining Machine
}

\author{
Alexandre SPIESER, Atanas IVANOV
}

\author{
Brunel University
}

\section{School of Engineering \& Design, Advanced Manufacturing and Enterprise Engineering}

\begin{abstract}
Electrochemical micromachining ( $\mu \mathrm{ECM})$ is a nonconventional machining process based on the phenomenon of electrolysis. $\mu \mathrm{ECM}$ became an attractive area of research due to the fact that this process does not create any defective layer after machining and that there is a growing demand for better surface integrity on different micro applications including microfluidics systems, stress free drilled holes in automotive and aerospace manufacturing with complex shapes etc.
\end{abstract}

This work presents the design of a next generation $\mu \mathrm{ECM}$ machine for the automotive, aerospace, medical and metrology sectors. It has 3 axes of motion $(\mathrm{X}, \mathrm{Y}, \mathrm{Z})$ and a spindle allowing the tool-electrode to rotate during machining.

The linear slides for each axis use air bearings with linear DC brushless motors and 2nm-resolution encoders for ultra precise motion. The control system is based on the Power PMAC motion controller from Delta Tau. The electrolyte tank is located at the rear of the machine and allows the electrolyte to be changed quickly. This machine features two process control algorithms: fuzzy logic control and adaptive feed rate.

A self-developed pulse generator has been mounted and interfaced with the machine and a wire ECM grinding device has been added. The pulse generator has the possibility to reverse the pulse polarity for on-line tool fabrication.

Keywords - Micro ECM, PECM, micro manufacturing, micro ECM machines, electrochemical micromachining (EMM)

\section{INTRODUCTION}

\subsection{FUnDAMENTALS}

Electrochemical micromachining is a non-conventional manufacturing process used as an alternative to conventional mechanical machining and non-conventional manufacturing processes for electrically conductive materials.

Electrochemical machining (ECM) is based on the process of electrolysis. It is very popular for material volume removal and shaping the anode using DC current by using complex shaped cathode electrodes. The anode (workpiece) and the cathode (tool-electrode) are both submerged in a constantly renewed electrolytic solution and a voltage is applied. The resulting current passes through the system and a chemical reaction takes place. Anodic dissolution occurs, material is removed and the workpiece is shaped according to the features of the cathode [1]. This machining process uses non-toxic electrolytes such as a sodium nitrate $\left(\mathrm{NaNO}_{3}\right)$ and sodium chloride $(\mathrm{NaCl})$ aqueous solutions [2].

Recent developments in this area aim at the use of much smaller electrodes with a smaller inter-electrode gap size for machining complex features. This requires improving severely the resolution of the anodic dissolution and respectively the achieved accuracy. These developments led to the appearance of a new area of ECM machining technology defined as 'Pulsed Electrochemical Machining' (PECM) [3-5]. PECM uses voltage pulses instead of continuous voltage enabling a better feature resolution [4].

This new technology can nowadays be applied at a micrometre scale and is called 'Pulse Electrochemical Micromachining' (also referred to as $\mu$ ECM, $\mu$ PECM, EMM, PECMM, PEMM) [6-9]. In most papers, the frequency and the pulse duration are respectively much higher and much shorter than in initial PECM $[10,11]$.

This technique exploits the capacitive properties of the electrical double layer (EDL) at the electrode/electrolyte interfaces: it has been demonstrated that the electrical model of the electrochemical cell is a RC circuit [11-15]. The charging constant $\left(\tau=\mathrm{RC}_{\mathrm{DL}}\right.$, where $\mathrm{C}_{\mathrm{DL}}$ is the overall capacitance of the cell and $\mathrm{R}$ is the electrolyte resistance) of the EDL depends on the distance between the tool and the workpiece (which actually corresponds to the charging current path): the further the tool is from the workpiece surface, the longer the charging time of the EDL will be. By using this property, the localisation of the material removal can be controlled very accurately by setting the pulse duration according to the charging time of the EDL.

This machining technology is being developed to meet the increasing demand driven by progress made in aerospace (aero-engine blades [16] and gas turbine blade cooling system [17]), microelectronics [18], automotive (requirement for smaller fuel injection nozzles holes with complex shape in combustion engines), electronics (miniaturization of components), medical and biomedical fields [19-21]. It enables the machining of micro-size features with high accuracy and high aspect ratio in materials with high hardness and stiffness (or in the materials that are very hard to machine conventionally because they are very brittle such as Indium Antimonite (InSb)) [22].

\subsection{REVIEW OF EXISTING ECM AND $\mu$ ECM MACHINES}

Most of the commercially available machines are ECM sinking machines and micro features are made by copying the shape of the tool-electrode. ECM manufacturers are 'Winbro Group' who offer stem drilling machines and die sinking machines [23], EMAG also offer die sinking ECM machines [24] and pECM systems [25] provides the European market with a range of ECM sinking machines from Russia ("ET" series manufactured by Indec [26]). 
There is no great deal of $\mu \mathrm{ECM}$ machines on the market. The literature review reported two purpose-built machines able to perform $\mu \mathrm{ECM}$ milling using simple shaped electrodes. The first one has been developed by ECMTEC [27] (now part of EMAG $\mathrm{GmbH}$ ) and is commercially available in table-top and standard models [28]. The second machine has been reported in China and is a table-top machine [29] developed for research purposes. This machine is able to perform on-line tool fabrication by Block Electrical Discharge Grinding (BEDG), whereas the EMAG machine does not seem to have this capability for electrode preparation. Such machines are usually developed and used in laboratory conditions mainly for research purposes and the available documentation regarding them is very limited.

Sequential on-line tool machining followed by workpiece machining has been reported in laboratory experiments but it seems that none of the commercially available machines have the capability to perform it [30]. The reported work used two different electrolytes: $\mathrm{KOH}$ to fabricate the tool and then $\mathrm{HCl}$ to machine the workpiece. Having to manage two different electrolytes is a big constraint in the design of a machine for industrial applications because the system has to be rinsed and different tanks must be used to avoid contamination.

\section{Methodology And Design}

\subsection{JUSTIFICATION AND SPECIFICATIONS OF THE BUILD}

Products are becoming smaller, lighter and more compact. Furthermore, standards and quality requirements are rising. Micro-machining is finding more applications in many products in the Aerospace, Automotive, Medical Device, Jewellery and Consumables industries. In order to stay competitive manufacturers have to produce parts that are less pricey, have better surface finishes and meet ever increasing product quality requirements. ECM is one of the processes gaining wider acceptance in this sector to machine parts more accurately.

The micro-machining sector is a very competitive sector, with many companies involved with newly developed technologies trying to make it into the market place. Success in this market is difficult and requires a good, stable and robust product that an end-user can install in their shop floor and start manufacturing. However in many cases the new products are still at a prototype stage and are relatively expensive due to the high development costs and at the same time there are many competing processes in the micro-machining sector.

Electro Chemical Machining (ECM) has been neglected as a micro-capable technology for many years. The process was used mainly for sinking processes, deburring, and was developed to work in the aerospace industry working on turbine blades in the form of STEM drilling. The major advantages of the process are the high removal rate (energy efficiency), simplicity of the process, there is also no associated electrode tool wear and there is no defective layer left after machining. The latter makes this process extremely desirable for aerospace, medical, MEMS and many other applications. In addition there is no debris left from the process which means that no post-processing of the workpiece is required. In the recent years Pulsed ECM has appeared where the removal of material in a specific area has became more controllable. However, the boundaries of the process are also not well known yet. This process, unlike mechanical processes, lies in the grey area of chemistry, electric pulses and mechanical structure of the machine tool capabilities.

With rising needs for miniaturisation, techniques for machining of components to achieve dimensions and tolerances in the order of $1 \mu \mathrm{m}$ and $10 \mathrm{~nm}$, with associated surface roughness as fine as $\mathrm{Ra} 1 \mathrm{~nm}$ are increasingly demanded. To that end, processes such as electrochemical (ECM) and electro-discharge (EDM) machining that have already been successfully employed in the aerospace, car, medical and other industries, for shaping, cutting and finishing, especially of hard alloys, are now receiving fresh attention for the fabrication of micro-components.

The ECM process needs to compete with these and it has advantages over some of the processes in that there is no tool wear, material hardness is not an issue. The quality of the surface finish that can be achieved is very high; there is no recast layer - which can be obtained from EDM and laser machining. However there are issues such as the electrolyte that is used which can lead to oxidation of the part if it isn't protected or cleaned immediately after processing, the stability of the process which can lead to poor quality, and the endusers knowledge of the technology.

There are some ECM systems available on the market that can match the quality of some of the micro manufacturing processes however they are prohibitively expensive with between $€ 350,000$ to $€ 500,000$ for a granite-based machine and they are normally not production capable. Therefore it is important to promote the advantages of ECM through ensuring that a machine can be developed and achieve the accuracy that the market demands, that can work in a production environment and can do so consistently. The machine should be at a price point to compete with the other technologies in that space and prove the quality of the process through the manufacturing of micron accuracy with high reproducibility.

It is also important to educate the market about the ECM process and to show the advances that have been made to bring it to the point where it is able to compete with the other technologies (such as electro-discharge machining (EDM)).

In spite of the accumulated knowledge and number of attempts to build test demonstrators there is still no commercially available system encompassing all the knowledge and offering new micro/nano technology with revolutionary capabilities. This is mainly due to the fact that the work on Micro ECM to date has been sporadic and not well organized. 


\subsection{SETUP}

The machine (Figure 1 and Figure 4) consists of different subsystems which will be detailed below:

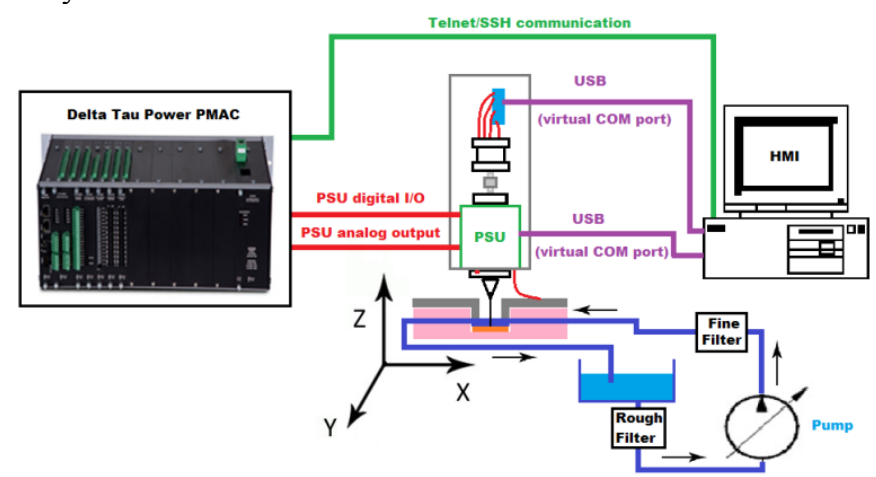

Figure 1. Schematic diagram of the developed micro-ECM machine

\subsubsection{GRANITE BASE}

The base of the machine is made out of granite, which has a very low thermal expansion coefficient, good damping characteristics and is very resistant to wear. Granite has always been a preferred material in the precision engineering sector.

The axes are arranged in a gantry configuration where the $\mathrm{X}$ axis supports the $\mathrm{Z}$ axis and the $\mathrm{Y}$ axis is directly mounted on the base (Figure 2). This gantry configuration enables a better overall machine stiffness in static and dynamic conditions [31].

The base is mounted on four rubber feet which isolate the machine mainly from low frequency vibrations.

\subsubsection{X, Y AND Z AXIS}

It has been reported in the literature [22] that the use of aerostatic bearings slides are the best way to reach precise and accurate motion in micro manufacturing applications. Air bearings feature frictionless and backlash-free motion, high acceleration capabilities, high accuracy and easy maintenance. This system implements a direct drive system, which has proven to be the best choice in precision machining applications [32].

Custom aerostatic slides were designed manufactured to achieve the best performance (Figure 3). Each of the slides consists of a DC brushless linear motor with a trapezoidal hall sensor, a linear encoder readhead with its scale and an air bearing. The air bearings consist of a sliding cage which is made of brass assembled around a granite beam. A very specific groove pattern has been machined on the air bearing surface to improve stability $[33,34]$. The clearance between the brass plates and the beam surface has been optimized for better performance of the slides. These slides are actuated by linear brushless DC motors model LEM-S-3-S from Anorad.

A trapezoidal hall effect sensor is used to find the phase at motor start up [35]. The motors therefore have two feedback sensors for control: 1) the trapezoidal Hall Effect sensor and 2) the linear position encoder.

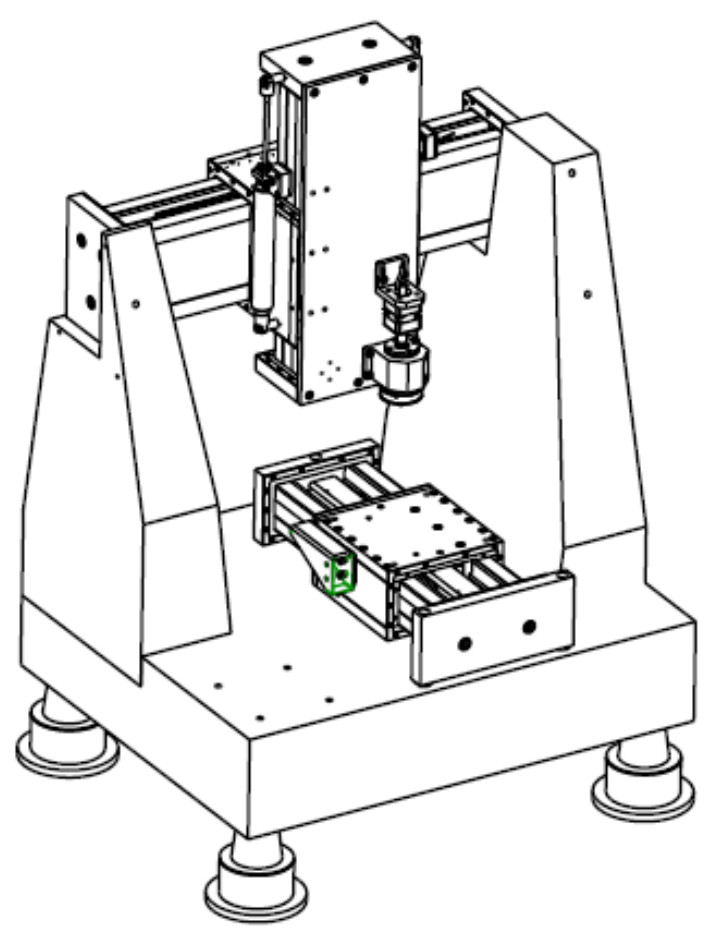

Figure 2. 3D view of the assembled machine

Both of these feedback devices are interfaced with the motion control system via an interface board Delta Tau ACC24E-2, which can control up to 4 axes simultaneously.

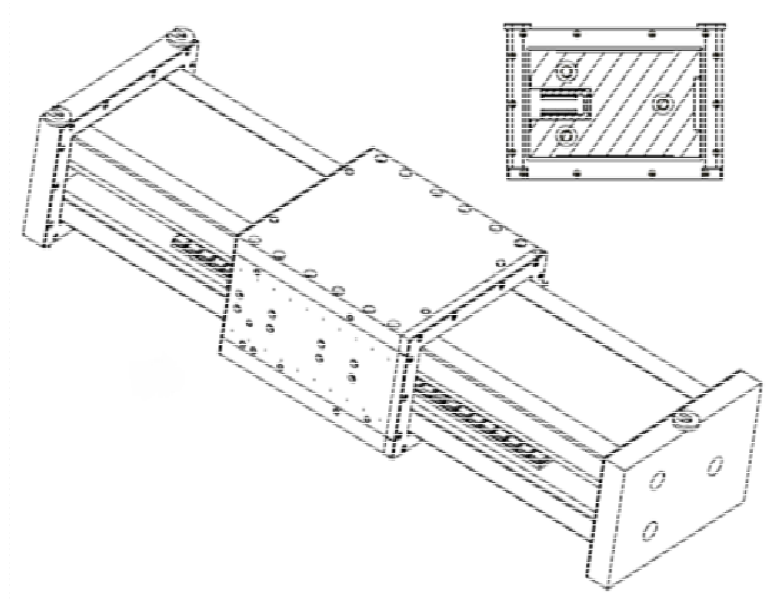

Figure 3. View of the assembled $\mathrm{X}$ axis and its cross-section

Linear motors have several advantages over screw driven systems:

- High Velocity

- High Acceleration

- Smoothness Of Motion (no friction)

- High Accuracy and Repeatability 
- High Stiffness

- Low Maintenance and high Life Expectancy

- Possibility for Clean Room And Vacuum Applications

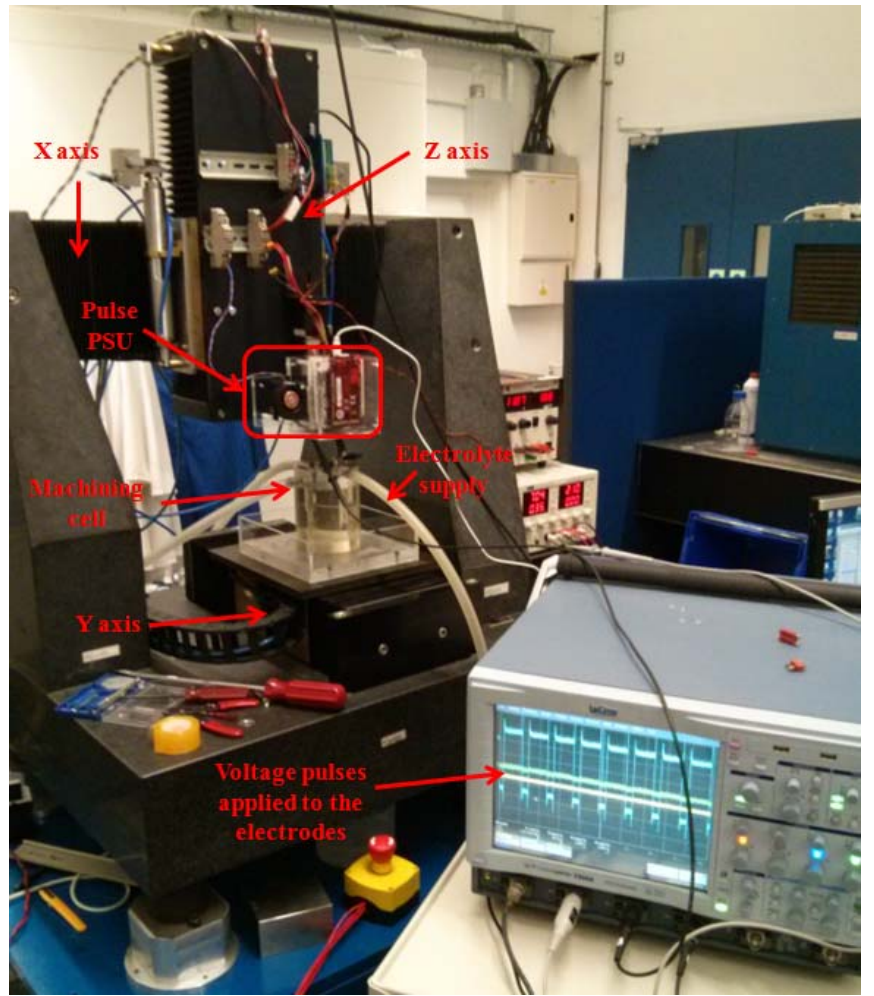

Figure 4. Picture of the developed Micro ECM Machine

For the $\mathrm{Z}$ axis, the linear motor is mounted vertically, and the weight of the slide is supported by frictionless air cylinders. The weight of the $Z$ slide is cancelled by adjusting the pressure into the air cylinders so that the force of the motor is only used to move the slide. This avoids motor overheating and prevents the tool from crashing into the workpiece in case of power loss. Brakes are also mounted onto the air cylinders and are activated if there is no air pressure, which prevents the slide from crashing.

The encoder receiver frequency of the motion control system is set to $40 \mathrm{MHz}$, which allows a maximum speed of $0.054 \mathrm{~m} / \mathrm{s}$ on each axis. This speed is more than sufficient because the tool feed rates during the machining process is very low. The $2 \mathrm{~nm}$ encoder resolution of the position feedback system allows a very precise motion of the slides. A reference mark is located in the middle of the scale and is used at initialization to setup the axis (during phase and home search).

The encoder system is made of a read head, an interpolator and a scale. The selected models of these components are summarized in Table 1.

The slides are actuated using direct PWM amplifiers Geobrick from Delta Tau. Each drive can handle 2 axes and is directly controlled by the PWM control signals coming from the Power PMAC motion controller. The PWM frequency has been set to $12 \mathrm{kHz}$, which is the recommended frequency for DC brushless linear motors.

\begin{tabular}{|l|l|}
\hline Read head & $\begin{array}{l}\text { Renishaw TONIC READHEAD 5m } \\
\text { RELM/RSLM, Model T1011-50A. } \\
\text { Tonic, Linear, Standard Read head, for RSLM/RELM } \\
\text { Scales, all reference marks are output, cable length } \\
\text { 5m. With standard mini connector to mate with Ti/TD } \\
\text { interface. }\end{array}$ \\
\hline Interpolator & $\begin{array}{l}\text { Renishaw TI 10KD A 20 A } \\
\text { Digital, Tonic (Ti), Interpolation factor/resolution: } \\
\text { 2nm (10KD), Line driven E output; All alarms (A), } \\
\text { Minimum receiver clock frequency (40 MHz), } \\
\text { Options: A = P/Q limits - 'active high', standard } \\
\text { reference mark. }\end{array}$ \\
\hline Scale & $\begin{array}{l}\text { Renishaw Scale - RSLM-SS-20U3A-0430-A } \\
\text { Standard, high accuracy stainless steel scale, with a } \\
\text { pitch of 20 } \mu \text { m, a cross section of 15mm X 1.5mm and } \\
\text { a spar length of 430mm. }\end{array}$ \\
\hline
\end{tabular}

\subsubsection{SPINDLE}

The spindle (Figure 5) rotates the electrode during machining in order to reduce the influence of the asymmetric imperfections of the tool-electrode (run out). This spindle uses a stepper motor, which allows precise positioning when toolelectrodes with different shapes are needed (triangle, square etc.). The model of the stepper motor is ST4218L1806-LCNEU from Nanotec which can be controlled using a SMCI331 drive. The step angle of the motor is 1.8 degrees with an accuracy of $+/-5 \%$. The drive communicates with the HMI using a USB port.

In $\mu \mathrm{ECM}$ tool electrodes with simple shapes (cylindrical or semi-cylindrical) are used in most cases. The electrical connection of the cathode is complex to achieve because the tool is spinning: energy pulses must be reliably transmitted to the rotating element [36].

In the case of high frequency power supply and high current it is not suitable to use the traditional carbon or silver brushes because the transmission of high current has a detrimental effect on them and they do not work well at high frequency (parasitic inductance). At the moment there is no good solution on the market such as a system transmitting high frequency signals and high current to a spinning electrode and at the same time to be located as close as possible to the IEG (with a minimal length of metal conducting the pulses).

The solution adopted by the authors was to develop a purpose built spindle (Figure 5) using precision bearings and to have the transmission of the signals to be done via a ring with microfiber carbon brushes. This type of ring is normally used for shaft grounding and bearing protection, and is able to handle high current at high frequencies [37]. To improve the electrical contact between the brushes and the tool-electrode, a silver coating was applied on the surface of the electrodeholder. This setup makes a reliable connection between the PSU and the rotating parts of the spindle which holds the toolelectrode. 


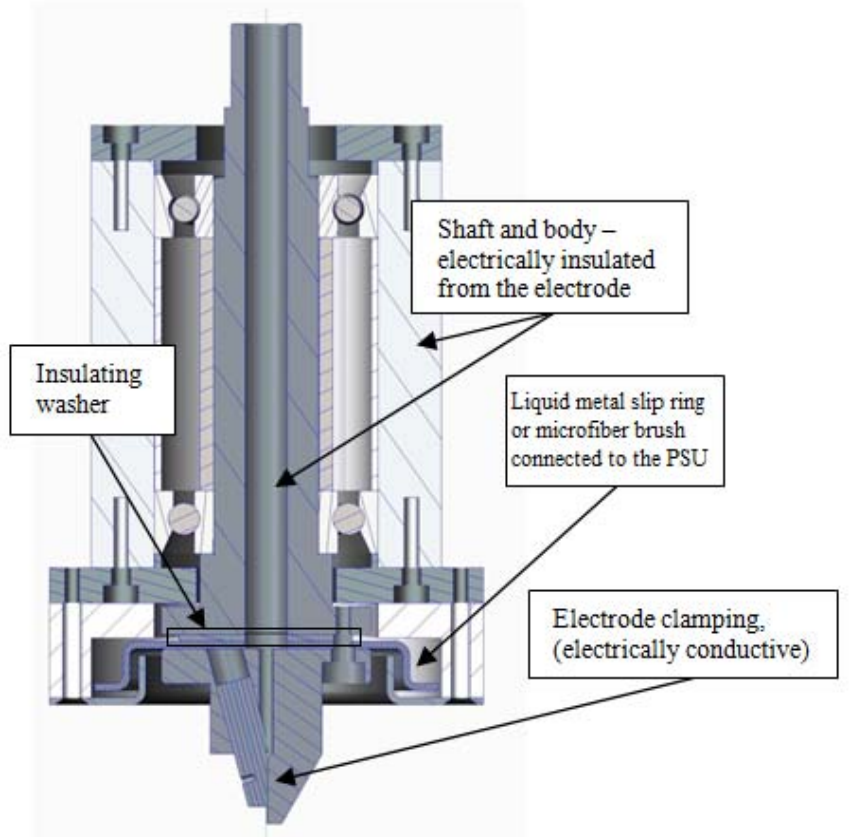

Figure 5. Cross section of the developed spindle for the $\mu$ ECM machine. For safety reasons, the mercury slip ring was later replaced by a ring with microfiber carbon brushes.

\subsubsection{MOTION CONTROLLER}

The control system and logic is one of the most innovative parts of the machine. As special process control algorithms needed to be developed, a controller with an open architecture was chosen in order to facilitate the development. Open architecture controllers offer great programming flexibility by allowing the developers to modify the system to suit their needs. The Delta Tau Power PMAC suited perfectly to this requirement: it can run PLCs and programs which are either written in $\mathrm{C}$ or in PMAC script language (which is a proprietary programming language from Delta Tau).

The Power PMAC is a single board computer which can be interfaced to an extensive range of compatible Delta Tau motion control, analogue input/output and digital input/output boards. The Power PMAC runs a Linux Debian distribution of which the kernel has been patched with the open-source real time extension Xenomai to give real time capabilities to the operating system [38]. The real time capabilities of the control system are essential to provide the machine with a deterministic behaviour in order to achieve the desired motion accuracy but also for safety reasons.

The Delta Tau Power PMAC CPU board is placed into a UMAC rack (Power UMAC configuration) (Figure 6) and interfaced with the following boards:

- ACC24E-2 4 axes interface board: this motion control board allows the Power PMAC to control up to 4 axes. The inputs of this board are the encoders and the hall sensors of every axis. This board is also interfaced with the direct pulse width modulation (PWM) amplifiers: the outputs of this board are the
PWM control signals that switch the power semiconductors in the drive.

- ACC36UK: this analogue input board is made of 16 analogue inputs which have a 16bit resolution. Analogue signals can be acquired at a frequency of 1 $\mathrm{kHz}$ for all channels and $16 \mathrm{kHz}$ on a single channel. This board is mainly used to acquire the peak value of the measured machining current.

- ACC65E: this digital input/output board is used to receive logic signals from the pulse power supply and all the safety related components. Its outputs are used to switch on relays and enable/disable features on the pulse power supply.

The controller also provides safety features such as over current protection and software and hardware position limits.

At each power up, the controller requires a home search move on all axes in order to set up the coordinate system of the machine: the slides are energized and move slowly towards the home position until the controller receives a specific pulse triggered by the read head when it crosses the 'home' reference mark on the scale.

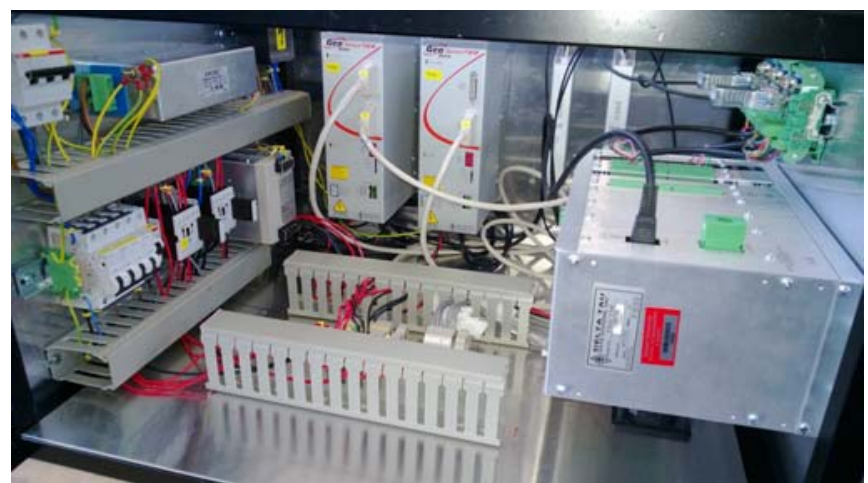

Figure 6. A picture of the electrical cabinet with the Power UMAC modular system.

\subsubsection{MACHINING CELL AND ELECTRICAL CONNECTIONS}

The electrochemical machining cell (Figure 7) has been designed to machine workpieces which have the shape of a coin. These parts were provided by the company Delphi (UK) and used in the fuel injection system of diesel engines. The electrochemical cell has 3 holes: 1 electrolyte inlet delivering the fresh electrolyte to the working zone and 2 electrolyte outlets taking the already used electrolyte to the filtering station.

In electrochemical machining the electrical connections must not be exposed to the effect of the working electrolyte. The part to be machined is clamped using a cap that is bolted on the top of the cell. This cap not only maintains the workpiece in position, but it is also made of conductive material (stainless steel) and connects the workpiece to the pulse PSU. The cap is also able to clamp a wire which can be used to perform electrochemical turning (Figure 8 (c)) to manufacture micro-probes and tools, but also to dress the 
electrode and eliminate run-out issues. This functionality is an alternative solution to the BEDG process of the machine developed in China[29].

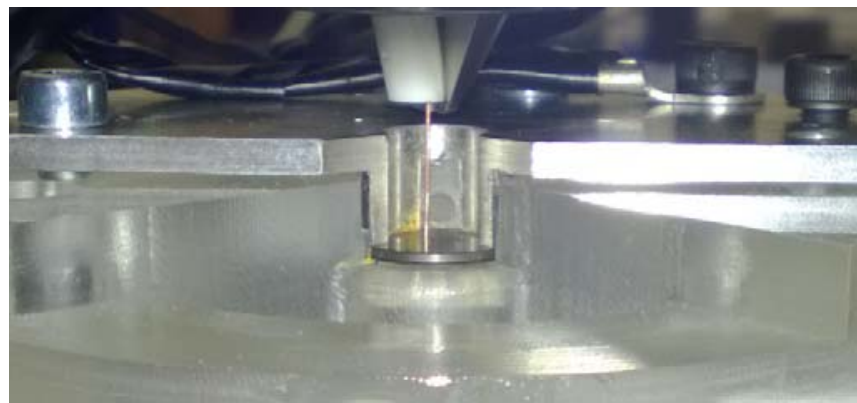

Figure 7. Picture of the workpiece (coin) being clamped by the cap and making electrical contact with a copper electrode.

One of the critical parameters of the $\mu \mathrm{ECM}$ process circuitry is the inductance of the cables connecting the PSU to the electrodes [39]. The parasitic cable inductance increases the rise time of the voltage pulses especially for pulse durations below $1 \mu \mathrm{s}$. At high frequency, the impedance of the cables becomes so big that only a portion of the output power is delivered to the IEG and the pulses are distorted. The cabling therefore limits the frequency at which machinining can occur and problems have been reported above $1 \mathrm{MHz}[40]$. To solve this issue, special low inductance cables should be used and their length must be minimised.

The use of coaxial cables to minimise cable inductance have also been reported [41]. This would mean that the PSU has to 'be positioned as close as possible at the gap connection' [39]. The solution adopted by the authors to minimize the cable length was to mount the pulse PSU directly on the $\mathrm{Z}$ axis, very close to the spindle (Figure 8).

\subsubsection{THE PULSE POWER SUPPLY UNIT (PSU)}

A self-developed programmable pulse PSU is used on the machine. This is a substantial development and it is described in a separate paper [42]. In this paper only the capabilities of the pulse PSU are summarized.

The architecture of this pulse PSU is different from what has been reported in the literature $[36,39]$ because it uses 6 Power MOSFETs controlled by 4 independent logic channels. It is possible to set the frequency, the duty cycle, the over current protection (OCP) threshold level and the pulse shape. The range of values for these parameters are displayed in Table 2 whereas Figure 9 represents a summary of the different pulse shapes that can be programmed. The shape of the pulse has an influence on the electrical double layer (EDL): Kozak et al. stated that applying a bias voltage during the pulse off-time would neutralize the discharge of the EDL[6] whereas Burkert et al. encouraged the use of a negative bias voltage to accelerate the unloading/reloading process of the EDL [39].

The developed pulse PSU is equipped with an ultra fast overcurrent protection switching its semiconductors off with 50ns after a short-circuit has been detected [42].

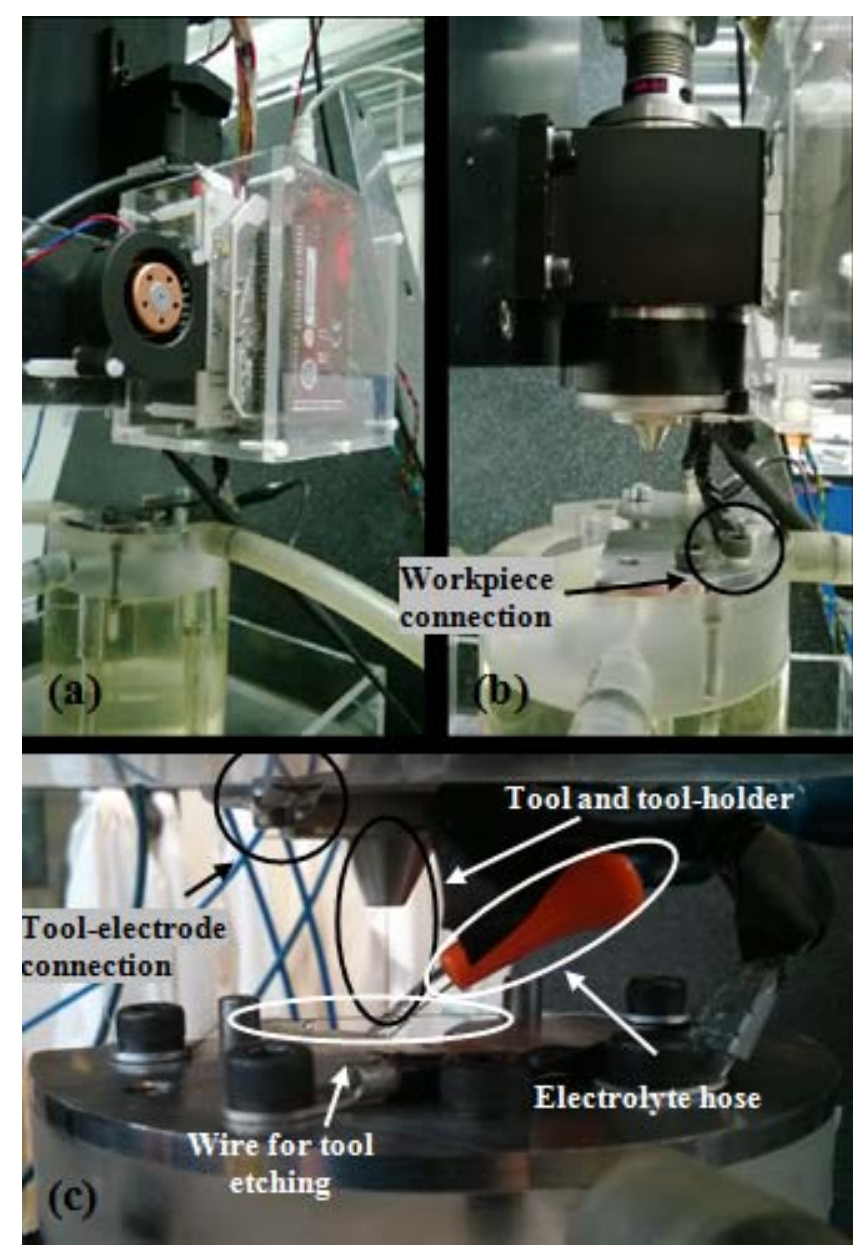

Figure 8. Pictures of the PSU mounted on the micro-electrochemical machine.

The PSU is interfaced with the Power PMAC using optocouplers to guarantee the protection of the microcontroller but also to shift the logic level from $3.3 \mathrm{~V}$ (on the PSU side) to $24 \mathrm{~V}$ (on the Power PMAC side).

\begin{tabular}{|l|l|}
\hline Description & Value range \\
\hline Voltage & $+/-10 \mathrm{~V}$ \\
\hline Frequency & $2 \mathrm{kHz}-8 \mathrm{MHz}$ \\
\hline Duty cycle & $0-100 \%$ \\
\hline OCP level & $0-6 \mathrm{~A}$ \\
\hline Modes & $1-8($ detailed in Figure 9$)$ \\
\hline
\end{tabular}

Table 2. The different pulse PSU parameters and their respective range of values

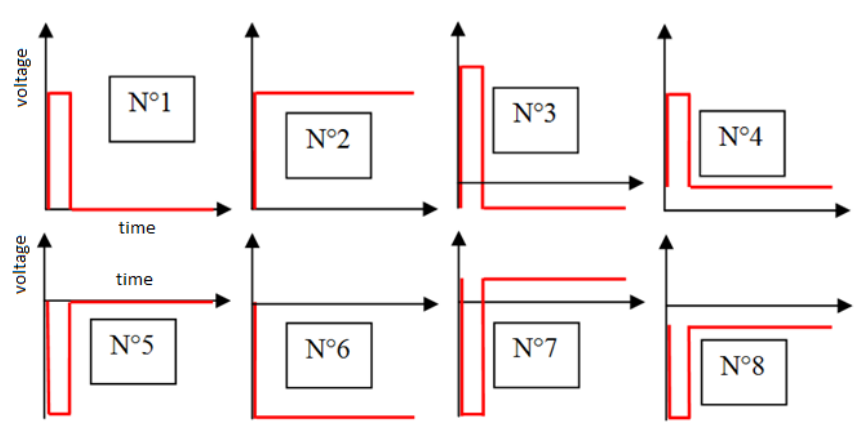

Figure 9. Drawing representing the different pulse shapes that can be produced with the self-developed pulse PSU [42] 


\subsubsection{ELECTROLYTE HANDLING}

The electrolyte delivery system consists of a pump and valves located at different places to be able to fully renew the electrolyte when different chemicals are used to machine specific materials. The chamber of the pump is made of chemical resistant material, allowing the use of corrosive electrolyte such as aqueous solutions of sulphuric acid or hydrochloric acid.

The system (Figure 10) includes also 2 filters: a rough $(10 \mu \mathrm{m})$ and a fine one $(1 \mu \mathrm{m})$. The rough filter is placed between the tank and the pump inlet, whereas the fine filter is between the outlet of the pump and the inlet of the machining cell.

Moreover, the tank of electrolyte is placed in a temperature controlled container not shown on the Figure 10.

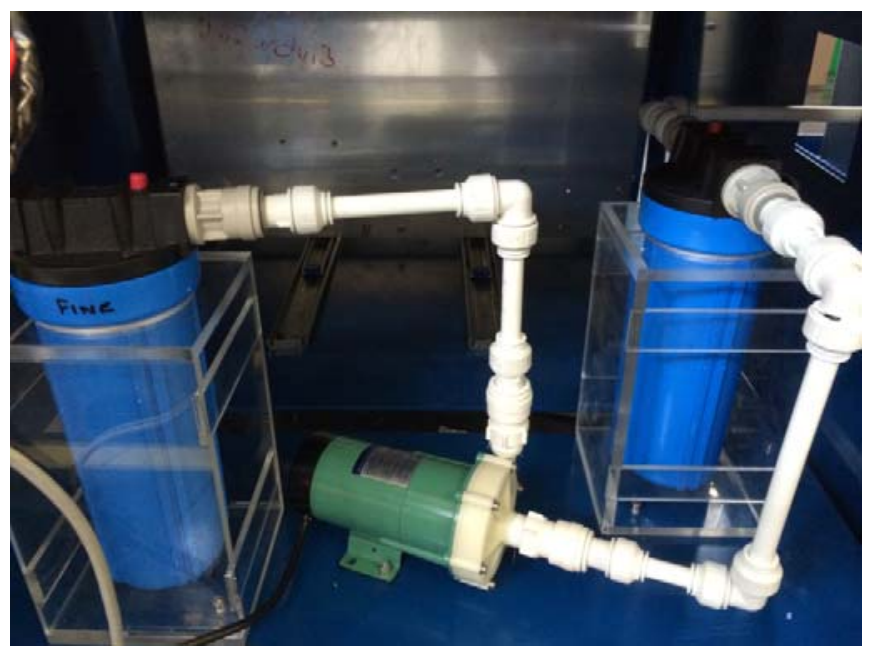

Figure 10. Picture of the electrolyte delivery system

\section{MACHINING PROCESS CONTROL AND SUPERVISION}

\subsection{INTERELECTRODE GAP INITIALIZATION AND CONTROL}

To define the inter-electrode gap, the following approach is used: A small voltage is applied to the electrodes of the electrochemical cell and the tool-electrode is moved towards the workpiece until a short-circuit is detected. When the shortcircuit occurs, the machine switches to a different mode where it will search the exact position where contact has been made. This stage is done by a state machine programme which is described in Figure 11. This method helps define the position of the workpiece surface with a precision better than $0.1 \mu \mathrm{m}$. From this position, the tool is retracted by the initial gap distance, which is set to $5 \mu \mathrm{m}$ by default but it could be user specified.

The major difficulties come from the cleaning the surfaces of the workpiece which especially involves removing the electrolyte drops from the electrodes in order to perform the measuring cycles reliably as this method is applicable only on dry surfaces.

\subsection{PROCESS MONITORING AND CONTROL}

Usually, in order to be able to control a process, the variation of a reliable parameter has to be measured and has to be significant enough in order to give a good representation of the current state of the process.

The control of the $\mu \mathrm{ECM}$ and ECM processes mainly refers to a constant adjustment of the tool position to maintain the interelectrode gap constant in order to achieve better accuracy, productivity and prevent the occurrence of electrical discharges (sparks). It "has been one of the main goals of ECM machine manufacturers and user industries such as turbine manufacturers" [5]. When drilling micro-holes, the feedrate of the tool-electrode should match the material removal rate of the process to maintain the gap size and reduce the chances for short-circuits to occur [43]. The interelectrode gap (IEG) is very hard to control because it cannot be measured directly.

The dimension of this gap can vary from a few $\mu \mathrm{m}$ to $100 \mu \mathrm{m}$ depending on the application and has a dramatic influence on the machining accuracy. During the machining process, the motion control logic mainly depends on the variation of the interelectrode gap (IEG) size. The different issues influencing the IEG size such as variation in local anodic current efficiency, short-circuits and variation of electrolyte conductivity in the IEG can be met during the ECM or $\mu \mathrm{ECM}$ process $[3,7,44]$. These events influence the material removal rate and therefore create a non-desired variation of the IEG.

Different control approaches have been experimented in the past [22] and for this project two control strategies have been developed. Both of these control approaches require the use of a custom made programmable pulse PSU with an ultra-fast Over Current Protection (OCP).

\subsubsection{GAP CONTROL USING FUZZY LOGIC}

The control strategy available on the machine is the use of a fuzzy controller to adjust the IEG according to a desired machining current. The use of this approach for the ECM processed was pointed out by Labib et al. [45] who highlighted the necessity for the controller to have decision making capabilities. Since the PECM process is very hard to mathematically model, conventional control approaches such as proportional-integral-derivative (PID) or state space controllers are limited and based on the linearisation of the process function (and therefore approximation). They observed that the occurrence of sparking was efficiently prevented when fuzzy logic control (FLC) was applied to the ECM process and encouraged further research to develop FLCs for the EMM process. Moreover, it is worth mentioning that fuzzy logic was also used to control the process in EDM, Wire-EDM [46, 47] and Electro-Chemical Discharge Machining (ECDM) [48, 49]. 


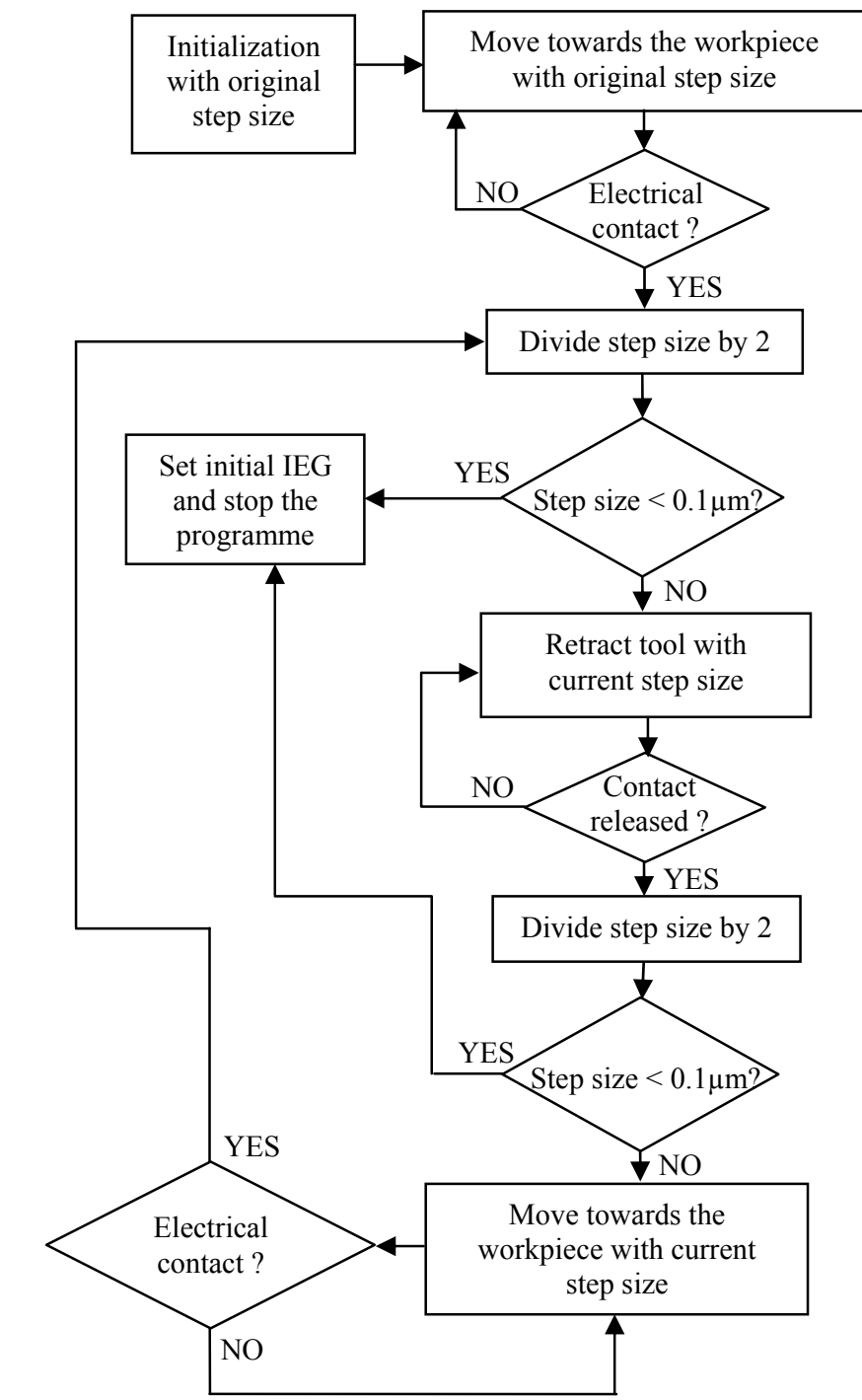

Figure 11. Flowchart describing the programme to set the initial IEG

\subsubsection{GAP CONTROL USING ADAPTIVE FEED RATE}

The second control strategy is the use of an adaptive machining algorithm decreasing the tool-electrode feed rate according to the number of times a short-circuit is detected.

This control algorithm has been developed in order to adapt the tool feed rate according to parameters calculated throughout the machining time:

- Number of OCP events (short-circuit situations)

- Times and positions at which the OCP events occurred

- Overall feed rate of the tool (calculated by using the start position, the current position and the elapsed machining time)

- Instantaneous feed rate (calculated after a very short time interval)

- Approximation of MRR using the OCP times and positions

When the adaptive feed rate algorithm has enough data to influence the feed rate, it activates itself.
This algorithm assumes that the positions and times at which the short-circuits occur can be used to calculate and adapt the feed rate in the $\mathrm{Z}$ direction. In the following illustration Error! Reference source not found., the positions and times at which the short-circuits occurred are stored in the Power PMAC.

Not all the short-circuits can be used to calculate the new feed rate of the tool: a filtering mechanism is used to filter out and ignore the consecutive short-circuits positions and times in order to only use representative data.

\subsubsection{TOOL ESCAPING METHODS}

The control algorithm during machining consists of a state machine which reacts to the unpredictable occurrence of short-circuits during the machining. In normal operation, the values of the signals "OCP" and "PSU ON" are checked to verify that no problem has been encountered. If everything is fine (when the PSU is pulsing and the OCP has not been triggered), the controller reads the value of the current on one of the channels of the data acquisition board and computes the appropriate step size necessary to maintain the interelectrode gap to a constant value. Controller constantly loops into that step unless an over current protection signal is triggered or the PSU stops pulsing. If the PSU stops pulsing, the controller interrupts the programme and display an error message on the HMI.

On the other hand, if an OCP event occurs (short-circuit situation), the controller will switch to a state which retracts the tool, restarts the power supply and goes back to the state of the fuzzy logic or adaptive control (Figure 12). The retraction of the tool can be simple or in two steps:

- If the Power PMAC motion controller is configured for the simple tool retraction, the tool will be retracted by a distance of which the value is stored in the variable DesRetractDistance.

- If the 'Back and Forward' mode is set then the tool will be retracted by the user-defined distance DesRetractDistance and then repositioned at a calculated relative position.

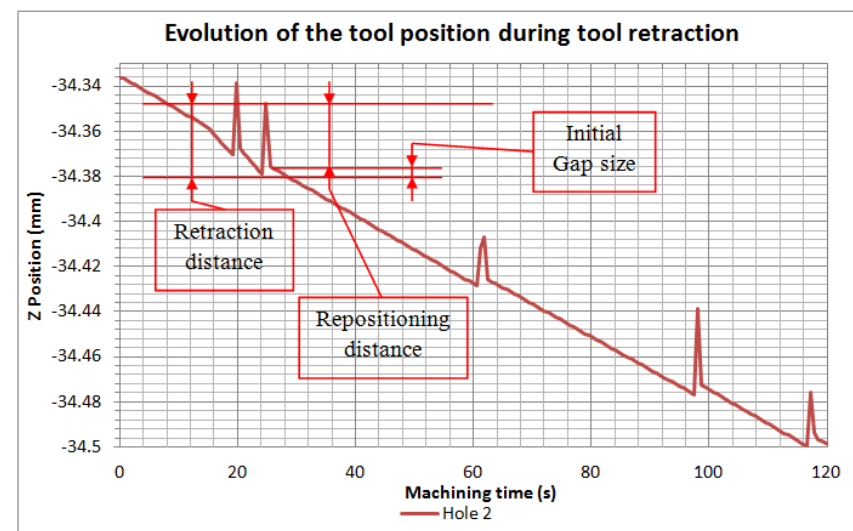

Figure 12. Graph illustrating the tool retraction followed by the repositioning to reset the IEG 
This specific algorithm is written in $\mathrm{C}$ and is considered as a PLC by the Power PMAC. The communication between the PSU and the Power PMAC is achieved via the HMI. Since the Power PMAC did not have the necessary drivers to communicate with the microcontroller on the PSU, this solution was adopted.

However, when the over current protection is triggered and the pulsing parameters do not need to be changed, the Power PMAC can trigger a restart of the PSU using the $4 \mathrm{I} / \mathrm{O}$ ports that have been implemented on the PSU.

Other PLCs written in PMAC script language run in parallel of the main control algorithm. The role of the PLCs nr. 2, 3 and 4 is to automate the setup of the motors, each motor is automatically setup (phase finding step, then home searching routine) when the user clicks on the button "Motor Setup" of the human machine interface (HMI).

Another PLC (plc1) is taking care of sending relevant data to the HMI using the Telnet communication protocol.

\subsection{The Human-Machine InTERFACE (HMI)}

A self-developed HMI connects directly to the motion controller (Power PMAC) and the pulse PSU and allows the user to setup and monitor the machining current, tool position and other essential machining parameters (Figure 13). This program has been written in $\mathrm{C}$ using the CVI/LabWindows IDE from National Instruments. The communication protocol used to connect with the Power PMAC is Telnet and the HMI is communicating to the PSU via USB using a virtual COM port. The refresh time period of the displayed values has been set to approximately $150 \mathrm{~ms}$.
The HMI is a very important aspect of the machine: It not only displays relevant information to the user, but also communicates with the PSU and the drive of the spindle.

The HMI stores all the machining data including the current waveforms and the evolution of the tool position. This data can be exported as a text file (.txt) which can then be opened with any standard office software.

\section{MACHINING RESULTS}

At the moment, the machine has been tested on $18 \mathrm{NiCr} 6$ alloys used in the automotive industry which is not an easy material to machine by ECM process (the parts that have been tested were disks provided by the automotive company Delphi UK).

Many types of electrolytes were used in electrochemical machining. For the experiments, $\mathrm{NaNO}_{3}$ mixed with a small amount of $\mathrm{HCl}$ was used as electrolyte. $\mathrm{HCl}$ was combined with other chemicals in many papers $[8,10,14,50-58]$ in concentrations varying from $0.01 \mathrm{M} \mathrm{HCl}$ [14] up to $3 \mathrm{M} \mathrm{HCl}$ [10]. In the following experiments, a mixture of $0.1 \mathrm{M} \mathrm{H}_{2} \mathrm{SO}_{4}$ and $0.5 \mathrm{M} \mathrm{NaNO}_{3}$ solutions was used as electrolyte.

The positions of the surfaces of the wire and workpiece were determined by electrical contact via the OCP circuitry of the PSU. The OCP was set to trigger at a very low threshold for this operation.

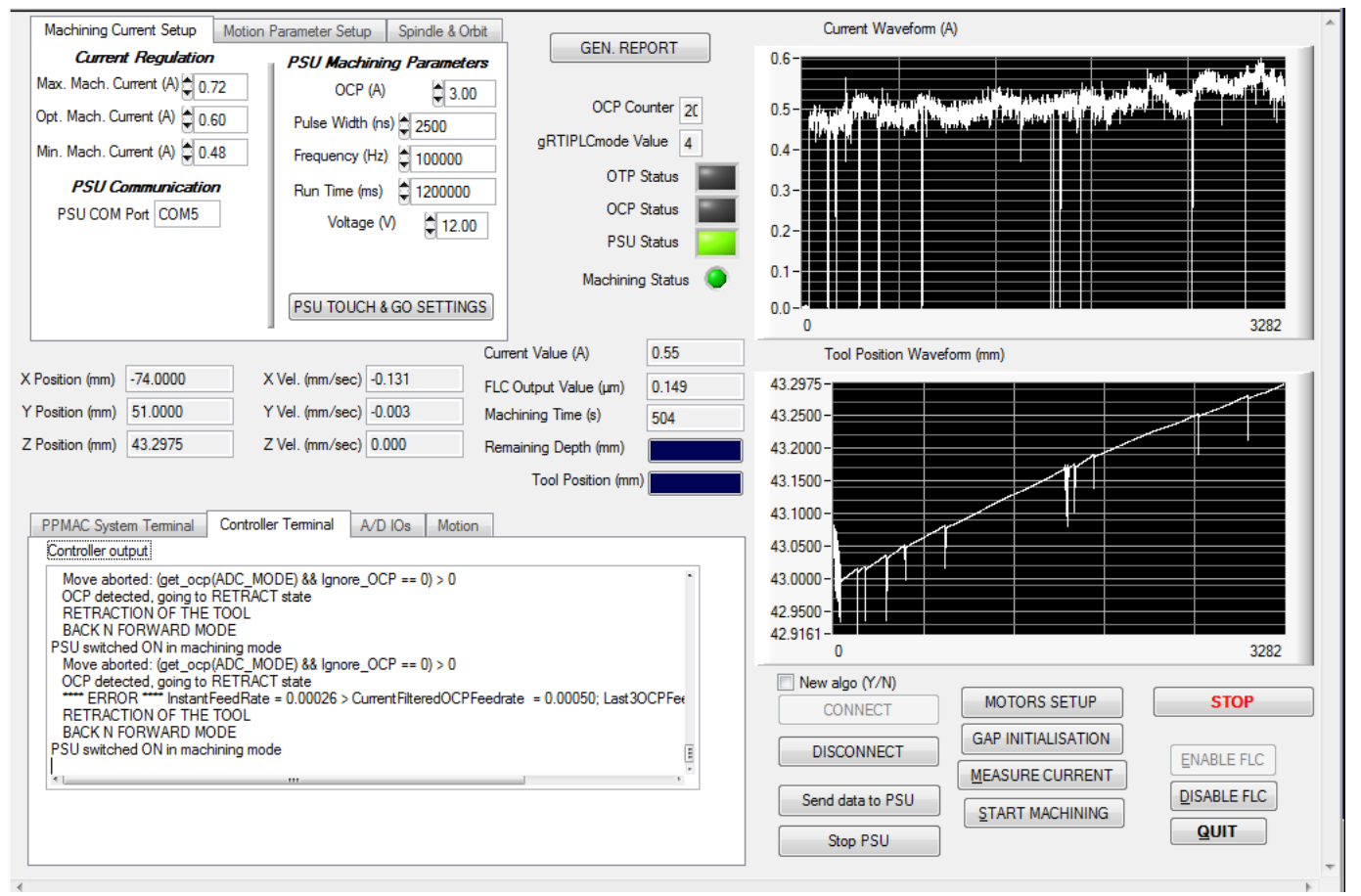

Figure 13. Screenshot of the HMI of the micro-ECM machine 


\subsubsection{TOOL FABRICATION FOLLOWED BY WORKPIECE DRILLING}

The workpiece was a disk made of $18 \mathrm{NiCr} 6$ alloy which was provided by the automotive company Delphi UK. The disk is $1.1 \mathrm{~mm}$ thick.

The electrode in the tool-holder had a diameter of $170 \mu \mathrm{m}$ and was made of WC-Co alloy ( $\mathrm{WC}+5 \% \mathrm{Co}$ ).

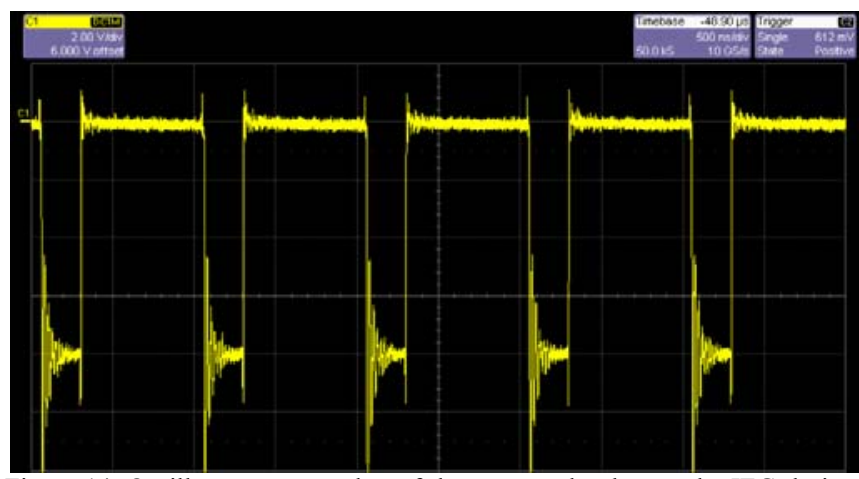

Figure 14. Oscilloscope screenshot of the measured pulses at the IEG during machining, $1 \mathrm{MHz}$ frequency, duty cycle of $25 \%$, pulse amplitude of $8 \mathrm{~V}$ and no offset during off-time $500 \mathrm{~ns} /$ div.
The micro tool was first etched to a diameter of $105 \mu \mathrm{m}$ via electrochemical grinding (Figure 8 (c)). The electrode was brought very close to the wire with a gap of $10 \mu \mathrm{m}$ and electrolyte was supplied to the system via a nozzle (Figure 8 (c)). The shaft was spinning at 600rpm during the etching process and was slowly fed down towards the wire while ultrashort pulses were delivered to the IEG. This process used the following parameters: $-7 \mathrm{~V}$ pulses with no offset (pulse shape $\mathrm{n}^{\circ} 5$ on Figure 9), at a pulse period of $500 \mathrm{~ns}$ and a $50 \mathrm{~ns}$ pulse duration. Overcurrent protection was set to $0.7 \mathrm{~A}$. The wire had a diameter of $200 \mu \mathrm{m}$ and was made of $\mathrm{Zn}$ coated brass.

From the graphs in Figure 17 it can be seen that the tool progression was linear, with a lot of OCP retractions during the first half of the machining session. The machining time was 3748s. The sidewalls of the tool are not insulated so it can be observed that the current increases when drilling at a bigger depth (because the tool sidewalls react with the inner walls of the hole). The pictures (Figure 15 and Figure 16) and diameter measurements have been taken with a Tesa-Visio 200GL.
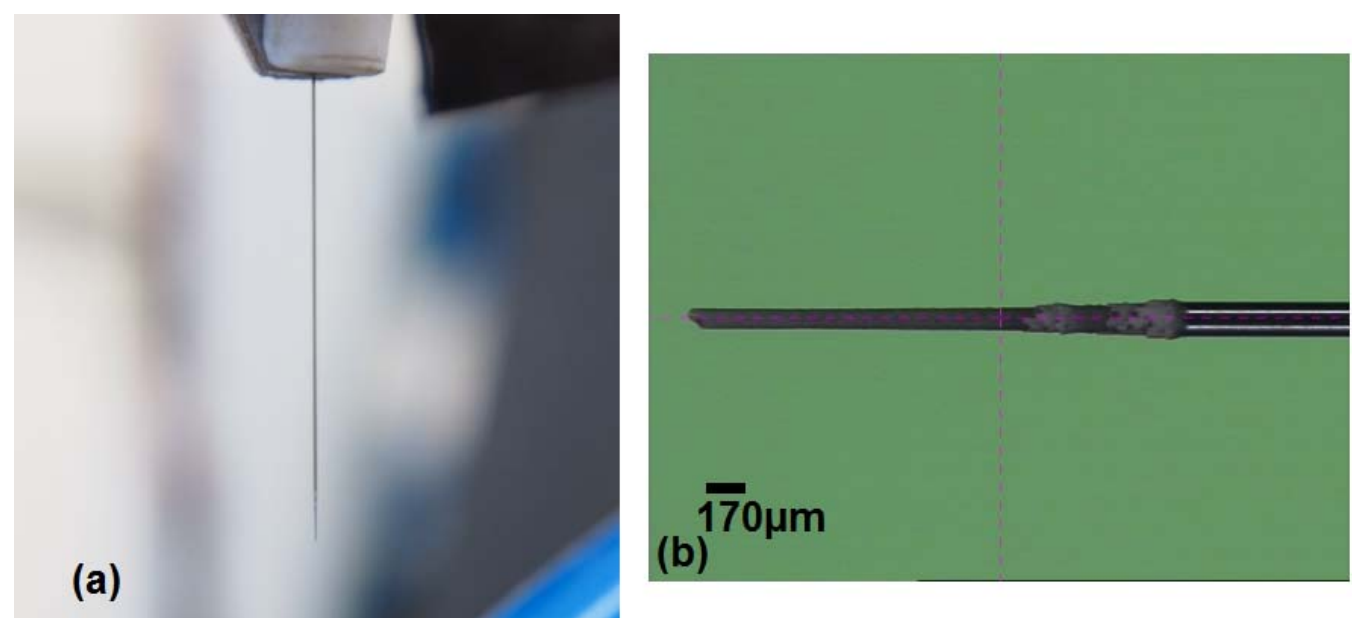

Figure 15. (a) Tool in the tool holder (b) Picture of the micro tip etched via Wire $\mu \mathrm{ECM}$ (electrochemical turning), a $\mathrm{NaNO}_{3}$ salt layer can be observed along the tool surface (WC-Co alloy, electrolyte $0.5 \mathrm{M} \mathrm{NaNO}_{3}+0.1 \mathrm{M} \mathrm{H}_{2} \mathrm{SO}_{4}$, pulse amplitude: $-7.5 \mathrm{~V}$, pulse duration: $50 \mathrm{~ns}$, pulse period: $500 \mathrm{~ns}$, feedrate: $0.3 \mu \mathrm{m} / \mathrm{s}$, diameter: $95 \mu \mathrm{m})$
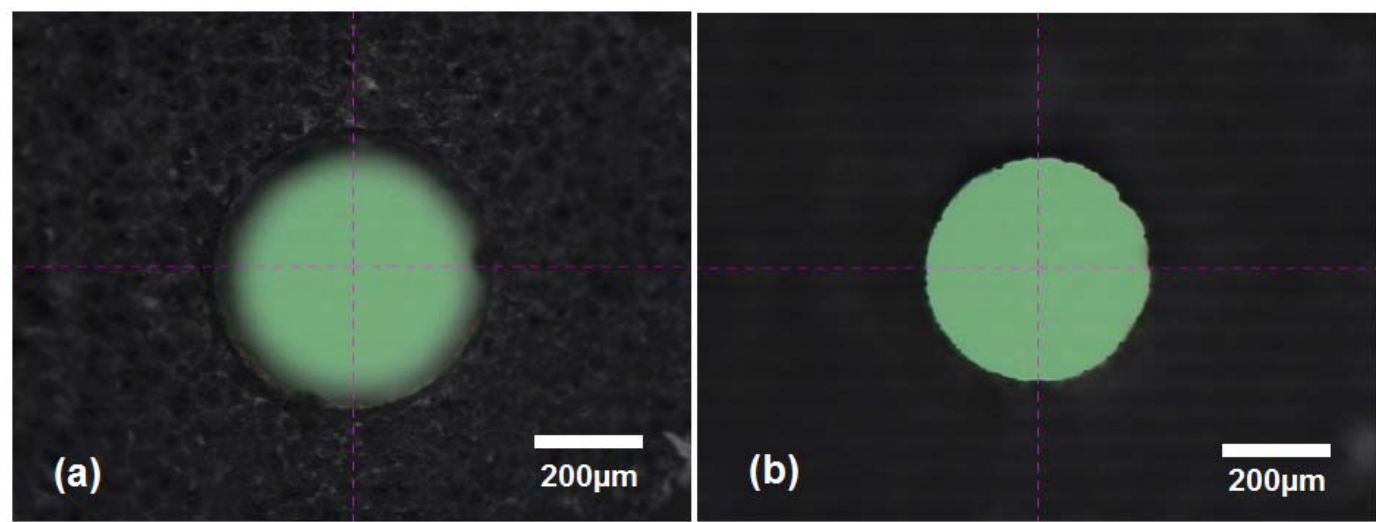

Figure 16. Picture of the hole fabricated by ECM with the WC-Co etched tool. (a) hole entrance, (b) hole exit (18NiCr6 alloy, depth: $1.1 \mathrm{~mm}$, hole entrance diameter: $517 \mu \mathrm{m}$, hole exit diameter: $414 \mu \mathrm{m}$, electrolyte $0.5 \mathrm{M} \mathrm{NaNO}_{3}+0.1 \mathrm{M} \mathrm{H}_{2} \mathrm{SO}_{4}$, pulse amplitude: $8 \mathrm{~V}$, pulse duration: $250 \mathrm{~ns}$, pulse period: $1 \mu \mathrm{s}$, feedrate: $0.3 \mu \mathrm{m} / \mathrm{s})$. 


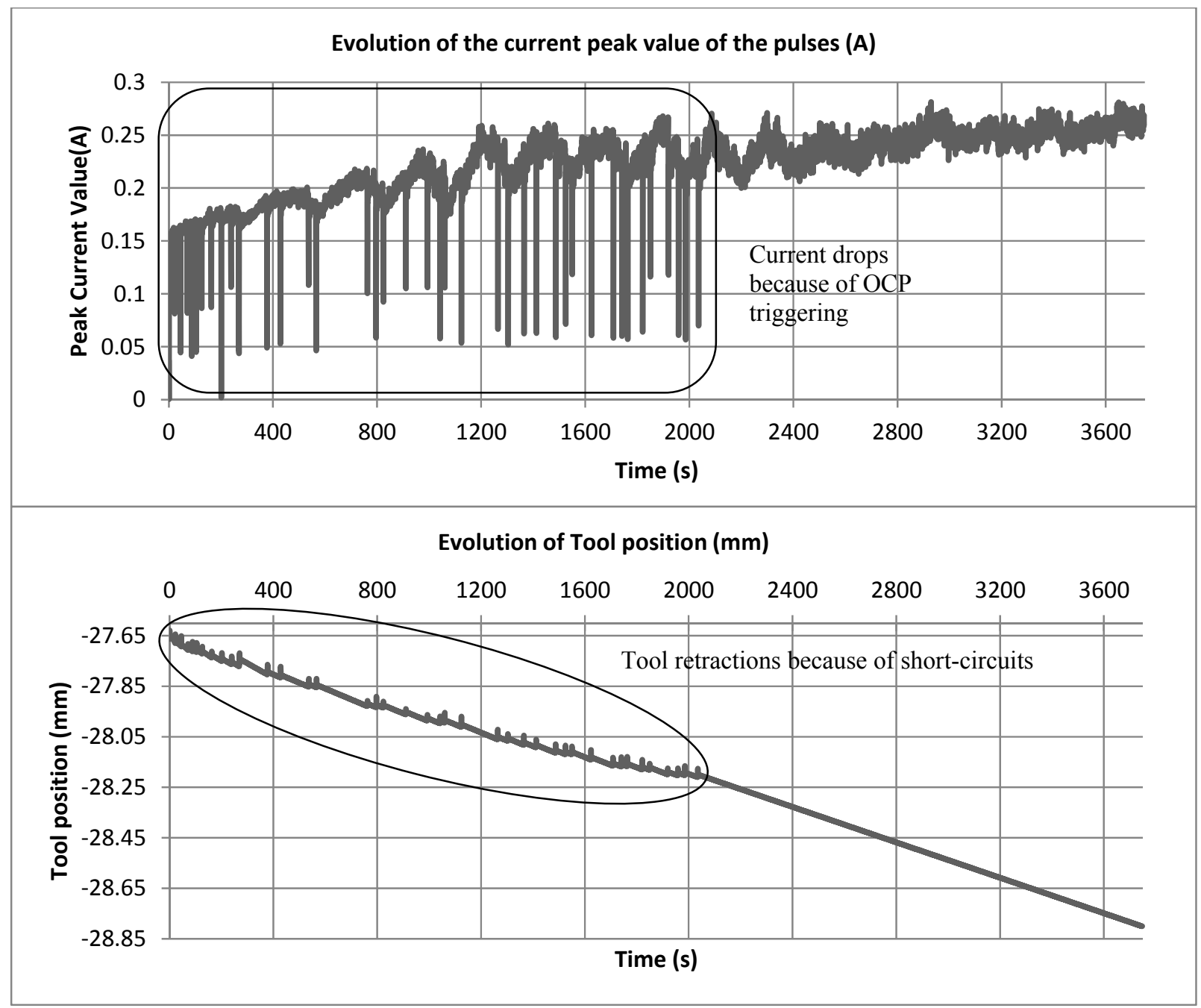

Figure 17. Graphs representing (a) the evolution of the current peak value of the pulses (in A) and (b) the evolution of the tool position (in mm) over time (in s) during the drilling process of the $18 \mathrm{NiCr} 6$ workpiece.

\subsubsection{MiCRO-TOOL FABRICATIONS}

The pulse PSU was also used to machine micro tools out of WC-Co electrodes $(170 \mu \mathrm{m}$ diameter $)$ via electrochemical grinding using the previously mentioned $200 \mu \mathrm{m}$ diameter wire. A very sharp tool (Figure 19) was fabricated by repetitively scanning the surface of the wire at a fixed gap. The tip of the tool measures $5 \mu \mathrm{m}$. The machining of this tool was faster than the hole-drilling process and took only 350 seconds.

Another technique was applied to produce the tool shown in Figure 20: the side gap between the micro tool and the wire was varied during the machining process to achieve this curved tool shape. The smallest diameter measured on that micro tool is $46 \mu \mathrm{m}$ and its tip is slightly bigger $(57 \mu \mathrm{m})$. The aim of this experiment was to fabricate a tool looking like the micro-probes used in coordinate-measuring machines (CMM).

The surface of the micro-tool was observed using optical equipment with the help of the National Physics Laboratory (NPL). It was determined that the roughness of the machined
WC-Co shaft in Figure 20 was $0.012 \mu \mathrm{m}$ Ra. In Figure 18 it can also be observed that the surface texture is very uniform.

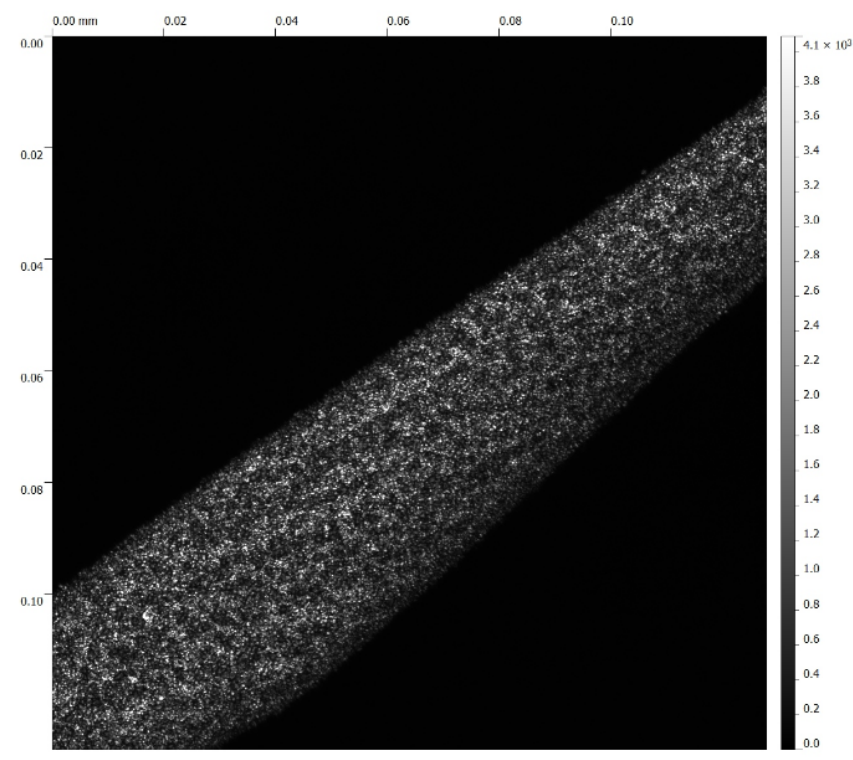

Figure 18. Micro-tool surface picture $(0.12 \mu \mathrm{m} \mathrm{Ra})$ 


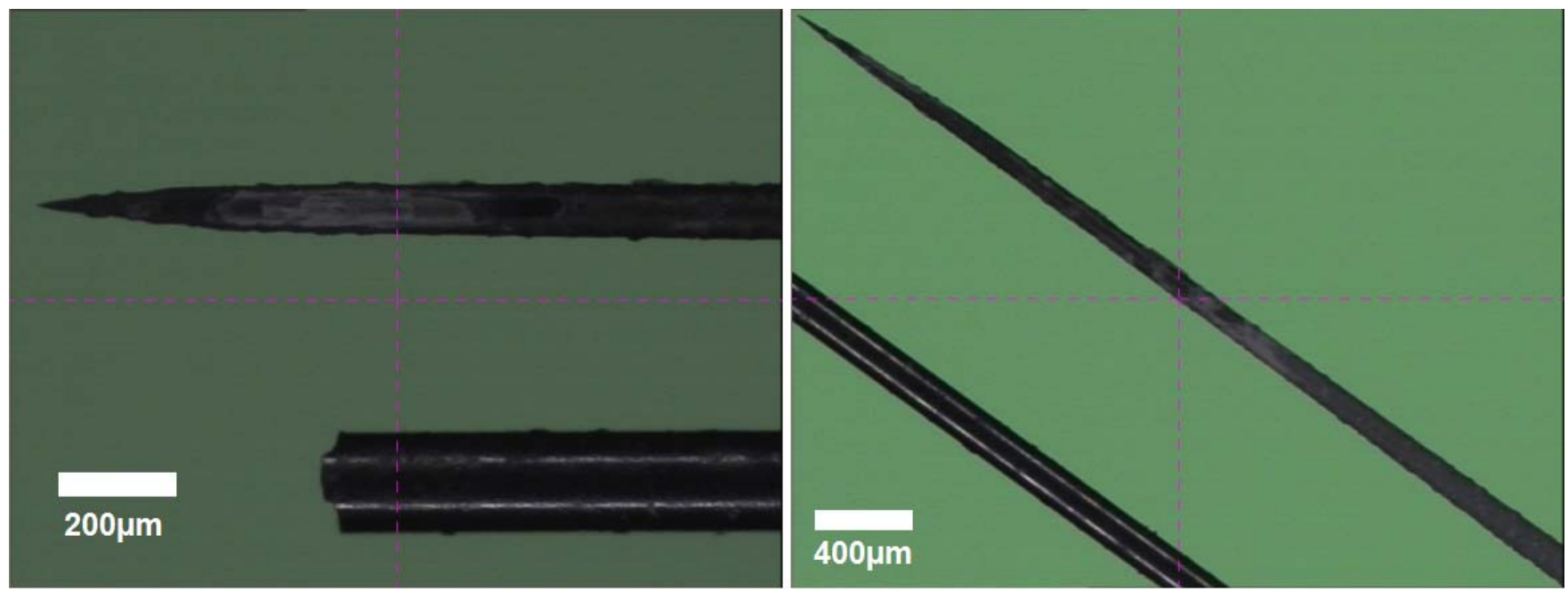

Figure 19. Tool of the shape of a needle made by micro electrochemical turning. A non-machined tool-electrode of $170 \mu \mathrm{m}$ is placed next to it for size comparison. (WC-Co alloy, electrolyte $0.5 \mathrm{M} \mathrm{NaNO}_{3}+0.1 \mathrm{M} \mathrm{H}_{2} \mathrm{SO}_{4}$, pulse amplitude: $-7.5 \mathrm{~V}$, pulse duration: $50 \mathrm{~ns}$, pulse period: $500 \mathrm{~ns}$, feedrate: $0.3 \mu \mathrm{m} / \mathrm{s}$, tip diameter: $5 \mu \mathrm{m})$
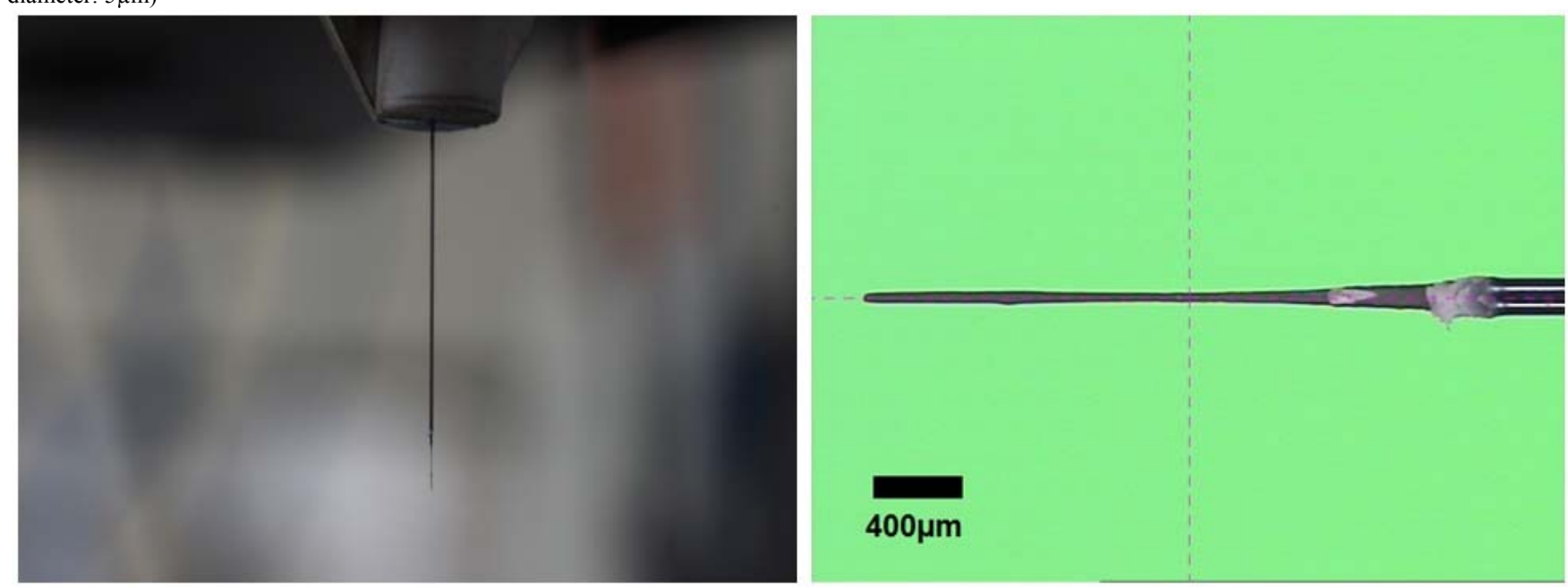

Figure 20. Micro-tool made by micro electrochemical turning. (WC-Co alloy, electrolyte $0.5 \mathrm{M} \mathrm{NaNO}_{3}+0.1 \mathrm{M} \mathrm{H}_{2} \mathrm{SO}_{4}$, pulse amplitude: $-7.5 \mathrm{~V}$, pulse duration: 50 ns, pulse period: $500 \mathrm{~ns}$, feedrate: $0.2 \mu \mathrm{m} / \mathrm{s}$, diameter of tip: $57 \mu \mathrm{m}$, smallest diameter measured: $46 \mu \mathrm{m}$ )

\section{DISCUSSION AND CONCLUSIONS}

In this paper, a fully operational electrochemical micromachining machine was presented and the following facts can be reported:

1) Use of air bearings for ultra precision and frictionless motion. The slides are equipped with encoders of $2 \mathrm{~nm}$ resolution, guaranteeing a motion accuracy below $0.1 \mu \mathrm{m}$.

2) Design of an innovative pulse PSU providing pulses with a frequency ranging from $2 \mathrm{kHz}$ to $8 \mathrm{MHz}$. The developed pulse PSU is also able to reverse pulse polarity and add a positive/negative biases during pulse off-time. The device is also equipped with an ultra-fast (50ns time delay) short-circuit protection.

3) The design of the electrochemical cell and the innovative pulse PSU implies that the developed $\mu \mathrm{ECM}$ machine is both able to perform on-line tool fabrication as well as workpiece machining without any intervention on the hardware (no need to change any cable connection). Pulse PSUs with similar performance and functionalities have not been reported.

4) The control system provides with two innovative gap control strategies: (1) The use of fuzzy logic was not reported in $\mu \mathrm{ECM}$ applications and is available on this machine for machining holes with side-insulated tool-electrodes. (2) An adaptive feed rate algorithm adjusts the feed rate by doing a linear interpolation of the times and positions at which the short-circuits where detected.

This development can lead to various applications such as the drilling of micro-holes in hard to machine material for the automotive and aerospace sectors. Each of these applications will require the design of an adapted workpiece clamping system which should meet the electrical and spatial 
requirements for an optimal machining performance (short current path for high frequency, chemical resistant fixtures...).

Moreover, the machine can be used to fabricate micro-tools and micro-probes for the micro coordinate measuring machine (micro-CMM) sector.

The above results are encouraging, further work will be done to reduce the overcut and determine the optimal machining performance for the $18 \mathrm{NiCr} 6$ material. Moreover, different types of material will be machined and several frequency values will be tested. Further investigation on the influence of the tool-electrode orbiting will be done to confirm the improvements observed in this paper.

\section{ACKNOWLEDGMENT}

The research reported in this paper is supported by the European Commission within the project "Minimizing Defects in Micro-Manufacturing Applications (MIDEMMA)" (FP72011-NMP-ICT-FoF-285614).

\section{REFERENCES}

1. McGeough JA (1974) Principles of Electrochemical Machining. Chapman and Hall, London

2. Datta M, Harris D (1997) Electrochemical micromachining: An environmentally friendly, high speed processing technology. 42:3007-3013. doi: 10.1016/S0013-4686(97)00147-3

3. Wei B (1994) Modeling and analysis of pulse electrochemical machining. The University of Nebraska - Lincoln

4. Rajurkar KP, Kozak J, Wei B, McGeough JA (1993) Study of Pulse Electrochemical Machining Characteristics. CIRP Ann - Manuf Technol 42:231-234. doi: 10.1016/S0007-8506(07)62432-9

5. Rajurkar KP, Wei B, Kozak J, McGeough JA (1995) Modelling and Monitoring Interelectrode Gap in Pulse Electrochemical Machining. CIRP Ann - Manuf Technol 44:177-180. doi: 10.1016/S0007-8506(07)62301-4

6. Kozak J, Rajurkar KP, Makkar Y (2004) Study of Pulse Electrochemical Micromachining. J Manuf Process 6:714. doi: 10.1016/S1526-6125(04)70055-9

7. Kozak J, Rajurkar KP, Makkar Y (2004) Selected problems of micro-electrochemical machining. J Mater Process Technol 149:426-431. doi: 10.1016/j.jmatprotec.2004.02.031

8. Zhang Z, Zhu D, Qu N, Wang M (2007) Theoretical and experimental investigation on electrochemical micromachining. Microsyst Technol 13:607-612. doi: 10.1007/s00542-006-0369-7
9. Kamaraj AB, Sundaram MM (2013) Mathematical modeling and verification of pulse electrochemical micromachining of microtools. Int J Adv Manuf Technol. doi: 10.1007/s00170-013-4896-y

10. Cagnon L, Kirchner V, Kock M, et al. (2003) Electrochemical Micromachining of Stainless Steel by Ultrashort Voltage Pulses. Zeitschrift für Phys Chemie 217:299-314. doi: 10.1524/zpch.217.4.299.20383

11. Schuster R, Kirchner V, Allongue P, Ertl G (2000) Electrochemical Micromachining. Science (80- ) 289:98-101. doi: 10.1126/science.289.5476.98

12. Schuster R (2007) Electrochemical microstructuring with short voltage pulses. Chemphyschem A Eur J Chem Phys Phys Chem 8:34-39. doi: 10.1002/cphc.200600401

13. Schuster R, Kirchner V (2004) Method for electrochemically processing material. US 6689269 B1

14. Trimmer AL, Hudson JL, Kock M, Schuster R (2003) Single-step electrochemical machining of complex nanostructures with ultrashort voltage pulses. Appl Phys Lett 82:3327. doi: 10.1063/1.1576499

15. Kock M, Kirchner V, Schuster R (2003) Electrochemical micromachining with ultrashort voltage pulses-a versatile method with lithographical precision. Electrochim Acta 48:3213-3219. doi: 10.1016/S00134686(03)00374-8

16. Li Z, Ji H (2009) Machining Accuracy Prediction of Aero-engine Blade in Electrochemical Machining Based on BP Neural Network. Proc. 2009 Int. Work. Inf. Secur. Appl. (IWISA 2009) ISBN 978-952-5726-06-0. ACADEMY PUBLISHER, Qingdao, China, pp 9-12

17. Wang M, Zhu D, Qu NS, Zhang CY (2007) Preparation of Turbulated Cooling Hole for Gas Turbine Blade Using Electrochemical Machining. Key Eng Mater 329:699704. doi: 10.4028/www.scientific.net/KEM.329.699

18. Datta M, Landolt D (2000) Fundamental aspects and applications of electrochemical microfabrication. Electrochim Acta 45:2535-2558. doi: 10.1016/S00134686(00)00350-9

19. Kamaraj AB, Sundaram MM, Mathew R (2013) Ultra high aspect ratio penetrating metal microelectrodes for biomedical applications. Microsyst Technol 19:179186. doi: 10.1007/s00542-012-1653-3

20. Lu X, Leng Y (2005) Electrochemical micromachining of titanium surfaces for biomedical applications. J Mater Process Technol 169:173-178. doi: 10.1016/j.jmatprotec.2005.04.040 
21. Bhattacharyya B, Doloi B, Sridhar PS (2001) Electrochemical micro-machining: new possibilities for micro-manufacturing. J Mater Process Technol 113:301-305. doi: 10.1016/S0924-0136(01)00629-X

22. Spieser A, Ivanov A (2013) Recent developments and research challenges in electrochemical micromachining ( $\mu \mathrm{ECM})$. Int J Adv Manuf Technol. doi: 10.1007/s00170-013-5024-8

23. Winbro Group Technologies (2012) Winbro Group Systems.

24. EMAG GmbH (2014) EMAG Website - ECM / PECM Machines.

25. pECM Systems pECM Systems Website.

26. Indec (2014) Indec "ET” ECM Machines. http://www.indececm.com/en/equipment/ekp/ekp/ET500-1\%26ET10001/. Accessed 26 Aug 2014

\section{ECMTEC GmbH (2012) ECMTEC Website.}

28. EMAG (2012) MicroECM Machine brochure EMAG.

29. Wang Y, Chen H, Wang Z, et al. (2010) Development of a Soft-Computer Numerical Control System for Micro Electrochemical Machining. 1:51-55.

30. Zhang Z, Wang Y, Chen F, Mao W (2011) A Micromachining system based on electrochemical dissolution of material. Russ J Electrochem 47:819-824. doi: $10.1134 / \mathrm{S} 1023193511070172$

31. Huo D, Cheng K (2008) A dynamics-driven approach to the design of precision machine tools for micromanufacturing and its implementation perspectives. Proc Inst Mech Eng Part B J Eng Manuf 222:1-13. doi: 10.1243/09544054JEM839

32. Nor MKM (2010) Development of the UMAC-Based Control System with Application to 5-Axis Ultraprecision Micromilling Machines. Brunel Univeristy

33. Stanev PT, Wardle F, Corbett J (2004) Investigation of grooved hybrid air bearing performance. Proc Inst Mech Eng Part K J Multi-body Dyn 218:95-106. doi: $10.1243 / 146441904323074558$

34. Luo X, Cheng K, Webb D, Wardle F (2005) Design of ultraprecision machine tools with applications to manufacture of miniature and micro components. J Mater Process Technol 167:515-528. doi: 10.1016/j.jmatprotec.2005.05.050
35. Anorad Linear Motor Division US. A (1999) LE SERIES Motor Integration Manual LEA, LEB, LEC \& LEM Linear Motors.

36. Zhang YJ, Tang YJ, Liu XK, et al. (2009) Development of Ultra-Short Pulse Power Supply Applicable to MicroECM. Mater Sci Forum 626-627:369-374. doi: 10.4028/www.scientific.net/MSF.626-627.369

37. Muetze A, Oh HW (2008) Design Aspects of Conductive Microfiber Rings for Shaft-Grounding Purposes. IEEE Trans Ind Appl 44:1749-1757. doi: 10.1109/TIA.2008.2006421

38. Barbalace A, Luchetta A, Manduchi G, et al. (2007) Performance comparison of VxWorks, Linux, RTAI and Xenomai in a hard real-time application. Real-Time ...

39. Burkert S, Schulze H, Gmelin T, Leone M (2009) THE PULSE ELECTROCHEMICAL MICROMACHINING ( PECMM ) - SPECIFICATIONS OF THE PULSE UNITS -. Int J Mater Form 2:645-648. doi: $10.1007 / \mathrm{s} 12289-009-0464-2$

40. Fan Z-W, Hourng L-W, Lin M-Y (2012) Experimental investigation on the influence of electrochemical microdrilling by short pulsed voltage. Int J Adv Manuf Technol 61:957-966. doi: 10.1007/s00170-011-3778-4

41. Park BJ, Kim BH, Chu CN (2006) The Effects of Tool Electrode Size on Characteristics of Micro Electrochemical Machining. CIRP Ann - Manuf Technol 55:197-200. doi: 10.1016/S0007-8506(07)60397-7

42. Spieser A, Ivanov A (2014) Design of a Pulse Power Supply Unit for Micro ECM. Int. J. Adv. Manuf. Technol.

43. Mithu MAH, Fantoni G, Ciampi J, Santochi M (2012) On how tool geometry, applied frequency and machining parameters influence electrochemical microdrilling. CIRP J Manuf Sci Technol 5:202-213. doi: 10.1016/j.cirpj.2012.07.006

44. Shin HS, Kim BH, Chu CN (2008) Analysis of the side gap resulting from micro electrochemical machining with a tungsten wire and ultrashort voltage pulses. J Micromechanics Microengineering 18:075009. doi: 10.1088/0960-1317/18/7/075009

45. Labib AW, Keasberry VJ, Atkinson J, Frost HW (2011) Expert Systems with Applications Towards next generation electrochemical machining controllers : A fuzzy logic control approach to ECM. Expert Syst Appl 38:7486-7493. doi: 10.1016/j.eswa.2010.12.074 
46. Çaydaş U, Hasçalık A, Ekici S (2009) An adaptive neurofuzzy inference system (ANFIS) model for wire-EDM. Expert Syst Appl 36:6135-6139. doi:

10.1016/j.eswa.2008.07.019

47. Lin C-T, Chung I-F, Huang S-Y (2001) Improvement of machining accuracy by fuzzy logic at corner parts for wire-EDM. Fuzzy Sets Syst 122:499-511. doi: 10.1016/S0165-0114(00)00034-8

48. Mediliyegedara TKKR, Silva a. KM De, Harrison DK, McGeough J a. (2005) New developments in the process control of the hybrid electro chemical discharge machining (ECDM) process. J Mater Process Technol 167:338-343. doi: 10.1016/j.jmatprotec.2005.05.043

49. Skrabalak G, Zybura-Skrabalak M, Ruszaj A (2004) Building of rules base for fuzzy-logic control of the ECDM process. J Mater Process Technol 149:530-535. doi: 10.1016/j.jmatprotec.2003.11.058

50. Lee ES, Baek SY, Cho CR (2007) A study of the characteristics for electrochemical micromachining with ultrashort voltage pulses. Int J Adv Manuf Technol 31:762-769. doi: 10.1007/s00170-005-0247-y

51. Sen M, Shan HS (2005) A review of electrochemical macro- to micro-hole drilling processes. Int J Mach Tools Manuf 45:137-152. doi: 10.1016/j.ijmachtools.2004.08.005

52. Kirchner V, Cagnon L, Schuster R, Ertl G (2001) Electrochemical machining of stainless steel microelements with ultrashort voltage pulses. Appl Phys Lett 79:1721. doi: 10.1063/1.1401783

53. Bilgi DS, Jain VK, Shekhar R, Kulkarni A V. (2006) Hole quality and interelectrode gap dynamics during pulse current electrochemical deep hole drilling. Int J Adv Manuf Technol 34:79-95. doi: 10.1007/s00170-0060572-9

54. Zemann R, Reiss PW, Schörghofer P, Bleicher F (2012) Cutting Edge Research in New Technologies - Chapter 1: Some Contributions at the Technology of Electrochemical Micromachining with Ultra Short Voltage Pulses. 3-29. doi: 10.5772/33560

55. Mukherjee SK, Kumar S, Srivastava PK (2005) Effect of Over Voltage on Material Removal Rate During Electrochemical Machining. 8:23-28.

56. Mithu M a. H, Fantoni G, Ciampi J (2011) The effect of high frequency and duty cycle in electrochemical microdrilling. Int J Adv Manuf Technol 55:921-933. doi: $10.1007 / \mathrm{s} 00170-010-3123-3$

57. Haisch T (2002) High rate electrochemical dissolution of iron- based alloys in $\mathrm{NaCl}$ and $\mathrm{NaNO} 3$ electrolytes. Max-Planck-Institut für Metallforschung Stuttgart

58. Lu Y, Liu K, Zhao D (2010) Experimental investigation on monitoring interelectrode gap of ECM with six-axis force sensor. Int J Adv Manuf Technol 55:565-572. doi: 10.1007/s00170-010-3105-5 